\title{
Two Italian Twin Registers for Research in Human Biology and Sport Science
}

\author{
Benedetta Casini, Monica Pittaluga, and Paolo Parisi \\ University of Sport and Movement Sciences of Rome-Foro Italico (IUSM), Rome, Italy
}

\begin{abstract}
Two Italian twin registers are described, the Register of Italian Twin Athletes (RITA) and the Twin Register of Rome (TERRY), developed in recent years at the newly established University of Sport and Movement Sciences of Rome-Foro Italico (IUSM). Ascertainment procedures, database, applications and current prospects are outlined, along with their research focus, which mainly consists of epidemiological and clinical research on the determinants of sport performance as well as on the role of genetic factors versus lifestyle, especially physical activity, in health and aging.
\end{abstract}

Scientific interest in twins developed about one century ago and applications of the twin method spread in the 1930s as an important tool for research in human genetics and, in particular, psychiatry and psychology. Despite this interest systematic collections of twin data were initially not frequent, and population-based registers were for a long time restricted to Scandinavia and a few other countries. In 1965 a World Health Organization (WHO) Meeting of Investigators on Methodology of Twin Studies carried out a survey and reported a total of 39 twin series, about twothirds of which were of the selected type (i.e., obtained from hospitals, schools, etc.) (WHO, 1966).

Interest in twins started fairly early in Italy where, following a first clinical observation in 1943, Gedda started a special outpatient service for twins at Rome's Medical Clinic. His systematic collection of data allowed him to put on record a twin series of about 1000 pairs, and publish several papers, eventually leading to his monumental Studio dei Gemelli (1951), partly translated into English as A Study of Twins (1961). He then started the journal, Acta Geneticae Medicae et Gemellologiae (1952) that has since long served as the international forum for twin research. Shortly after he established The Mendel Institute (1953), the only institution in the world to be especially devoted to twin care. Over the years, the initial twin series grew to a total of 16,000 records, including a few thousand pairs from special areas of investigation (e.g., 2000 from the Aosta Valley, about 1000 from Tuscany, etc.), but otherwise mostly from Rome and surroundings.

The Mendel Institute's register was clinically oriented: any twin pair would have access to free, general and specialized medical and dental care. The records were used for research purposes, and occasionally systematic twin series were directly studied or surveyed for specific purposes. Because twins were recruited on a voluntary basis, the register was not population-based; although in the 1970s, it could still have been considered to be fairly representative of the general population of Rome (Parisi et al., 1983). In later years, however, partly on account of changes in the Institute's policy and the generalized free medical care provided by the national health system, fewer pairs were recruited annually, and many old pairs were lost. As a result, the register became increasingly selective. Moreover, because of the lack of systematic maintenance, many changes of address or even residence were not recorded.

New approaches have been developed in recent years by our group (Parisi et al., 1998, 2001). Prompted by the interests and needs of a new university structure, and thanks to institutional support and a specific grant by the International Olympic Committee (IOC), two registers were developed for specific applications in the area of sport science, and more generally human biology, with special respect to development, aging and health studies. The first of these, the Twin Register of Rome (TERRY), is population-based and meant for epidemiological approaches and to directly address specific subpopulations or representative samples. The second, the Register of Italian Twin Athletes (RITA), is a specially selected register, listing all Italian twin athletes in various sports, as derived from the records of the respective Italian Sport Federations.

\section{The Twin Register of Rome (TERRY)}

Construction Procedures, Size and Characteristics

This register was conceived in the early 1990s with the aim to establish a database of all the twin pairs living in Rome to be used for research in human biology and sport science. When the law on privacy became effective in Italy (1996), the existence of the database was made known to the control body and the data were treated and protected as prescribed.

The basic source of information was the Resident Population Register of Rome, where all residents are listed by name along with related data on birth, family composition, address, and so forth. Birth records were initially searched and all residents sharing the following aspects were assumed to be twins: a) family name, b) date of birth, c) place of birth, and d) father's name. Then, for each individual

Address for correspondence: Dr. Benedetta Casini, Human Biology Center, University of Sport and Movement Sciences of Rome-Foro Italico, (IUSM) piazza L. de Bosis 6, 00194 Rome, Italy. Email: casini@iusm.it 
assumed to be a twin, sex and address were recorded. Cross-checks on the Mendel Institute's register, as well as on telephone directories and other sources were then carried out.

The register was developed in several stages, as described in the following.

1. At the first stage, carried out in 1994-95, a first cohort was ascertained, consisting of twin pairs born between 01.01.1950 and 31.12.1970. A total of 4898 pairs were ascertained - 1649 MM, 1672 FF, 1577 MF. This specific birth period was the first to be selected because many of these twins had been attending the Mendel Institute and some basic data about them were already available.

2. The second stage was performed in 1997, in order to collect data on elderly twins to be used for a research project on Life Style and Aging (LISA), particularly focused on the role of physical activity. All MM pairs born between 01.01.1933 and 31.12.1933 were ascertained, and from this subpopulation a random sample was extracted for the study, as described below.

\section{Table 1}

Twin Register of Rome - Number of Twin Pairs by Sex Combination and Year of Birth

\begin{tabular}{lrrrr}
\hline Year of birth & MM & FF & MF & Total \\
\hline $1910-15$ & 2 & 26 & 4 & 32 \\
$1916-20$ & 13 & 26 & 20 & 59 \\
$1921-25$ & 36 & 58 & 42 & 136 \\
$1926-30$ & 83 & 119 & 84 & 286 \\
$1931-35$ & 134 & 184 & 132 & 450 \\
$1936-40$ & 160 & 223 & 203 & 586 \\
$1941-45$ & 194 & 211 & 190 & 595 \\
$1946-50$ & 240 & 273 & 259 & 772 \\
$1951-55$ & 279 & 289 & 286 & 854 \\
$1956-60$ & 314 & 353 & 344 & 1011 \\
$1961-65$ & 485 & 486 & 450 & 1421 \\
$1966-70$ & 496 & 483 & 418 & 1397 \\
$1971-75$ & 543 & 527 & 453 & 1523 \\
$1976-80$ & 410 & 459 & 305 & 1174 \\
$1981-85$ & 319 & 310 & 255 & 884 \\
$1986-90$ & 369 & 373 & 318 & 1060 \\
$1991-94$ & 337 & 370 & 281 & 988 \\
Total & 4414 & 4770 & 4044 & 13,228 \\
\hline
\end{tabular}

3. In the third stage, between 1998 and 2000, data on the entire twin population of Rome (birth dates ranging from 01.01.1900 to 31.12.1994) were ascertained, with the same criteria described above. Data were computerized, but needed to be corrected in some cases, where because of record-keeping errors, double or complex names, or other causes, the "twins" happened to be just one individual who had been registered twice.

4. Finally, in 2000-2001, the register was updated to 31.12.2000. At present, the register includes a total of 26,732 twin individuals (13,228 twin pairs, 88 sets of triplets, and 3 sets of quadruplets), recorded in an Access database (Tables 1-3). The data can also be ordered by city district, so as to allow easier identification of suitable research samples.

It should be noted that, because of the structure of the municipality population data, the register includes only twins who are both residents of Rome at the time of ascertainment, independently of their birthplace. So, if the twins were born in Rome but one of them moved out, the pair was not included. Conversely, if the twins were not born in Rome, but lived there at the time of the study, they were included. This does not seem to affect the prevalence of twins in the register to any great extent, this being 9.6/ 1000 in the Roman population versus $9.2 / 1000$ in the general population of Italy.

\section{Research Applications}

The register is so far being used mostly in the context of the Life Style and Aging (LISA) project (Pittaluga et al., $1999,2001 \mathrm{a}, \mathrm{b})$. The project is focused on the role of a physically active lifestyle and of genetic effects in successful aging. At a cellular level, the interactions between physical activity, oxidative stress, and repair efficiency are studied. The association between physical activity and a decreased risk of age-correlated diseases seems to be well established, but it is unclear whether this is due to physical activity itself, to an associated lifestyle (Lee et al., 1997), or to underlying constitutional factors. The study involves the assessment of general health status and of lifestyle, specifically past and current physical activity, along with personality and other variables, in elderly $\mathrm{MZ}$ and $\mathrm{DZ}$ male twins.

A pilot study was carried out on 27 pairs of twins in their 70 s (mean age $71.0 \pm 2.6$ ), who were directly examined with respect to the following parameters (Pittaluga et al., 1999, 2001a):

\section{Table 2}

Twin Register of Rome - Number of Multiple Sets by Size, Sex Combination and Year of Birth

\begin{tabular}{lcccccccc}
\hline & \multicolumn{3}{c}{ Triplets } & \multicolumn{4}{c}{ Quadruplets } \\
& MMM & FFF & MFF & FMM & Total & MMFF & FFFM & Total \\
\hline $1910-44$ & - & 1 & 2 & 1 & 4 & - & - & - \\
$1945-69$ & 5 & 8 & 8 & 4 & 25 & - & - & - \\
$1970-94$ & 12 & 9 & 20 & 18 & 59 & 2 & 1 & 3 \\
Total & 17 & 18 & 30 & 23 & 88 & 2 & 1 & 3 \\
\hline
\end{tabular}




\section{Table 3}

Twin Register of Rome - Prevalence of MZ and DZ Pairs Estimated According to Weinberg's Method

\begin{tabular}{lcccc}
\hline \multirow{2}{*}{ Year of birth } & \multicolumn{2}{c}{ MZ pairs } & \multicolumn{2}{c}{ DZ pairs } \\
& $N$ & $\%$ & $N$ & $\%$ \\
\hline $1910-44$ & 732 & 36.17 & 1292 & 63.83 \\
$1945-69$ & 1895 & 35.87 & 3388 & 64.13 \\
$1970-94$ & 2513 & 42.44 & 3408 & 57.56 \\
Total & 5140 & 38.86 & 8088 & 61.14 \\
\hline
\end{tabular}

1. General aspects: zygosity, anthropometry, clinical history, personality traits (Bortner).

2. Health status: blood lipids and glycemia, cardiological profile (ECG, heart rate, blood pressure, vital capacity).

3. Lifestyle: education and past occupational levels, current and past physical activity, cultural and social interests, fat intake, smoking and alcohol intake.

4. Cellular response to oxidative stress: chromosomal aberrations (Pittaluga et al. 2001b; Vernole et al. 1999); micronuclei (Argentin et al., 2002).

5. Fitness assessment: force (Sbriccoli et al., 1999), balance (Pulejo et al., 1999), rhythmic ability (Persichini et al., 1999), maximal oxygen uptake (Alabiso et al., 1999).

Preliminary results are being analyzed and discussed. The study will then be extended to larger samples and specific attention will be devoted to the cellular response to oxidative stress induced by submaximal exercise in the elderly. Further applications of the register will be planned in other areas of human biology and sport science.

\section{Register of Italian Twin Athletes (RITA) Construction Procedures, Size and Characteristics}

The Register has been developed through a collaborative effort of several research groups at the former Higher State Institute of Physical Education (ISEF) of Rome (now University of Sport and Movement Sciences; IUSM) and 25 Sports Federations of the Italian National Olympic Committee (CONI). The Federations' records were searched and, out of a total of about 1,500,000 registered athletes, all those sharing the same family name and birthdate were selected and assumed to be twins. In a second ascertainment stage, identification was confirmed and addresses were obtained through direct contacts with hundreds of local clubs.

The Register currently includes a total of 4719 pairs of twin athletes (2561 MM, $1418 \mathrm{FF}, 740 \mathrm{MF}$ ), practicing sports such as: Track and Field, Canoeing, Cycling, Gymnastics, Golf, Judo, Sailing, Swimming, Boxing, Tennis, Basketball, Wrestling, and many others (Table 4). Collected data include addresses and birthdates.

Because of the structure of the data, all twins registered with each one of the Federations are necessarily concordant for the specific sport participation. In fact, the prevalence of twins in the total population of registered athletes is of $3.1 / 1000$, which is about one third of that in the general population.
The aim of this register was to contribute to the assessment of the role of genetic versus environmental factors in complex, presumably multifactorial variables, such as the response to physical exercise, adaptation and performance.

\section{Research Applications}

A number of twin studies were conducted in the past on such aspects as sport participation, motor skills, and learning (Gedda, 1955, 1960; Grebe, 1955; Kovar, 1975, 1981; Marisi, 1977; Sklad, 1972, 1975; Weiss, 1979), motor performance (Bouchard et al., 1986; Fagard et al., 1991; Klissouras, 1971), and response to training (Hamel et al., 1986; Proud'Homme et al., 1984; Saltin, 1969), but the determinants of motor performance are still far from clarified. In this context, the collection of a large representative series of twins who are also athletes with years of training, and the identification of top-level twin athletes to be studied directly in detail, can provide a unique resource for further research on such issues as heritability versus training in top-level performance, response to training programs, ages that can best be trained, functional adaptation, and so forth.

As a first research application, a questionnaire study was designed, involving the following steps:

1. Development of a basic questionnaire, addressing general aspects (individual and family data, zygosity, etc.) as well as specific items related to the respective sport discipline (training, performance, etc.);

2. mailing of the questionnaire to the twin athletes of each individual Federation; and

3. identification of top-level twin athletes, or other pairs of interest, for direct study.

Questionnaire studies were conducted on twin swimmers and tennis players (Parisi et al., 2001), and direct studies on Olympic level athletes in a competitive walking race (Klissouras et al., 2001).

All in all, completed questionnaires were obtained from 90 pairs of twin swimmers ( 45 MM, 29 FF, 14 MF, 1 set of triplets) and 130 pairs of tennis players (70 MM, $43 \mathrm{FF}$, $18 \mathrm{MF}$ ), in addition to several incomplete pairs. Basic information was collected with respect to the following: a) age, sex, and family variables, b) zygosity, c) anthropometry, d) left/right dominance, e) sport performance, f) participation motivation in sport, g) personality profile, and $\mathrm{h}$ ) sleep disturbances.

The data indicate strong zygosity and sex effects on sport selection, similarity being higher for $\mathrm{MZ}$ and males. As for sport participation and levels of performance, the previously reported higher concordance in $\mathrm{MZ}$ than in DZ pairs does not appear to be confirmed. Sampling selection effects must clearly play a role. In fact, the prevalence of twin pairs in the total population of registered athletes (about $1,500,000$ ) is only about $3.1 / 1000$, versus $9.2 / 1000$ in the general Italian population, suggesting that there must be many incomplete pairs, with co-twins practicing different sports or no sport at all.

Twin swimmers appear to be taller than their counterparts from the general Italian population of the same age. 
Table 4

Register of Italian Twin Athletes - Twin Athletes Participating in Various Sports as Assessed from the Records of the Respective Sport Federation (Twinning Rate in the Italian Population, 9.2\% (4.0 in MZ, 5.2 in DZ Pairs) ${ }^{* *}$

\begin{tabular}{|c|c|c|c|c|c|c|c|c|c|c|}
\hline \multirow{2}{*}{$\begin{array}{l}\text { Sport } \\
\text { Federation }\end{array}$} & \multirow{2}{*}{$\begin{array}{l}\text { Number of } \\
\text { registered } \\
\text { athletes }\end{array}$} & \multirow[t]{2}{*}{ MM } & \multirow[t]{2}{*}{$\mathrm{FF}$} & \multirow[t]{2}{*}{ MF } & \multirow[t]{2}{*}{ Total } & \multirow{2}{*}{$\begin{array}{l}\text { Number of } \\
\text { twins/1000 }\end{array}$} & \multicolumn{2}{|c|}{ MZ pairs* } & \multicolumn{2}{|c|}{ DZ pairs* } \\
\hline & & & & & & & $N$ & $\%$ & $N$ & $\%$ \\
\hline Baseball & 22,000 & 34 & 18 & 8 & 60 & 2.73 & 44 & 2.00 & 16 & 0.73 \\
\hline Basketball & 168,000 & 499 & 147 & 68 & 714 & 4.25 & 578 & 3.44 & 136 & 0.81 \\
\hline Boxing & 3000 & 17 & - & - & 17 & 5.67 & - & - & - & - \\
\hline Canoeing & 5,800 & 15 & 2 & 2 & 19 & 3.28 & 15 & 2.59 & 4 & 0.69 \\
\hline Cycling & 68,254 & 78 & 6 & 10 & 94 & 1.38 & 74 & 1.08 & 20 & 0.29 \\
\hline Gymnastics & 72,000 & 8 & 79 & 6 & 93 & 1.29 & 81 & 1.13 & 12 & 0.17 \\
\hline Golf & 44,000 & 37 & 12 & 39 & 88 & 2.00 & 10 & 0.23 & 78 & 1.77 \\
\hline Handball & 24,000 & 45 & 36 & 11 & 92 & 3.83 & 70 & 2.92 & 22 & 0.92 \\
\hline Hockey & 25,000 & 1 & 2 & - & 3 & 0.12 & - & - & - & - \\
\hline Judo & 55,000 & 196 & 56 & 60 & 312 & 5.67 & 192 & 3.49 & 120 & 2.18 \\
\hline Pentathlon & 1,000 & 1 & - & - & 1 & 1.00 & - & - & - & - \\
\hline Racing Boat & 600 & - & - & - & - & - & - & - & - & - \\
\hline Rowing & 7000 & 18 & 3 & 1 & 22 & 3.14 & 20 & 2.86 & 2 & 0.29 \\
\hline Rugby & 20,000 & 195 & 9 & 6 & 210 & 10.50 & 198 & 9.90 & 12 & 0.60 \\
\hline Sailing & 72,723 & 5 & 2 & 1 & 8 & 0.11 & 6 & 0.08 & 2 & 0.03 \\
\hline Shooting & 11,796 & 25 & 8 & 5 & 38 & 3.22 & 28 & 2.37 & 10 & 0.85 \\
\hline Soccer & 150,000 & 37 & - & 3 & 40 & 0.27 & 34 & 0.23 & 6 & 0.04 \\
\hline Swimming & 36,351 & 77 & 54 & 36 & 167 & 4.59 & 95 & 2.61 & 72 & 1.98 \\
\hline Table Tennis & 13,000 & 1 & 1 & - & 2 & 0.15 & - & - & - & - \\
\hline Tennis & 200,000 & 396 & 133 & 138 & 667 & 3.34 & 391 & 1.96 & 276 & 1.38 \\
\hline Track \& Field & 134,580 & 119 & 110 & 62 & 291 & 2.16 & 167 & 1.24 & 124 & 0.92 \\
\hline Volleyball & 193,279 & 214 & 553 & 66 & 833 & 4.31 & 701 & 3.63 & 132 & 0.68 \\
\hline Water Ski & 783 & - & - & 1 & 1 & 1.28 & - & - & - & - \\
\hline Winter Sports & 164,000 & 499 & 181 & 215 & 895 & 5.46 & 465 & 2.84 & 430 & 2.62 \\
\hline Wrestling & 5,699 & 44 & 6 & 2 & 52 & 9.12 & 48 & 8.42 & 4 & 0.70 \\
\hline Grand Total & $1,497,865$ & 2561 & 1418 & 740 & 4719 & 3.15 & 3217 & 2.15 & 1478 & 0.99 \\
\hline
\end{tabular}

Note: *estimated according to Weinberg's method ${ }^{* *}$ Birth period 1975-1984

Intra-pair correlations show similar values in $\mathrm{MZ}$ and DZ pairs with respect to height, weight, body-mass index (BMI), as well as sport performance and training patterns, revealing, at first sight, a low weight of genetic effects. However, these similarities may also be explained in terms of a lack of sufficient variability, because of the relative homogeneity in the swimmers' body structure and performance, or as a result of the selection of sports-concordant pairs, that can also imply the concordance in some physical features. When random pairs of non-related individuals are compared, their intra-pair correlations are considerably lower.

As for tennis players, concordance levels are similarly high in $M Z$ and DZ twins with respect to the level of practice (amateur or competitive) but low in technical strategies (kind of preferred competition, training program, etc.), thus pointing to limited genetic effects. Data, however particularly on performance, are somewhat contradictory. A study on laterality indicated a higher prevalence of lefthanded subjects among twin tennis players as compared to athletes in general (Casini et al., 2001).

Further applications of the Register may involve surveys of twin athletes practicing other sports, direct studies on some special case of top-level performance, and the analysis of specific biological, psychological or cultural variables related to motor behavior and athletic performance. It would also be interesting to mach these data referring to twin athletes concordant for sport practice with data derived from a general population twin register.

\section{$\overline{\text { References }}$}

Alabiso, A., Parisi, A., Pigozzi, F., Pittaluga, M., \& Parisi, P. (1999). Maximal oxygen uptake in elderly twins. Proceedings of the 4 th Annual Congress of the European College of Sport Science, Rome, 625, (Abstract).

Argentin, G., Caporossi, D., Parisi, P., Pittaluga, M., Tedeschi, B., Vernole, P., \& Cicchetti, R. (2002). Role of ageing on spontaneous and induced micronuclei in lymphocytes from elderly twins. Manuscript in preparation.

Bouchard, C., Lesage, R., Lortie, G., Simoneau, J. A., Hamel, P., Boulay, M. R., et al. (1986). Aerobic performance in brothers, dizygotic and monozygotic twins. Medicine and Science in Sports and Exercise, 18, 639-646. 
Casini, B., Pittaluga, M., \& Parisi, P. (1997). Physical activity, risk factors and aging - A pilot study on 60-year-old males. Proceedings of the 2nd Annual Congress of the European College of Sport Science, Copenhagen, 758-759, (Abstract).

Casini, B., Pittaluga, M., Prinzi, G., \& Parisi, P. (1999). A twin study on tennis players: Anthropometry, performance and laterality. Proceedings of the 4th Annual Congress of the European College of Sport Science, Rome, 693, (Abstract).

Casini, B., Pittaluga, M., Prinzi, G., \& Parisi, P. (2001). Handedness and motor behavior: A twin study. Journal of Sports Sciences, 19(8), 648-649.

Fagard, R., Bielen, E., \& Amery, A. (1991). Hereditability of aerobic power and anaerobic energy generation during exercise. Journal of Applied Physiology, 70(1), 357-362.

Gedda, L. (1951). Studio dei Gemelli. Roma: Orizzonte Medico.

Gedda, L. (1955). La valutazione genetica dell'atleta. Acta Geneticae Medicae et Gemellologiae, 4, 249-260.

Gedda, L. (1960). Sports and genetics: A study on twins (351 pairs). Acta Geneticae Medicae et Gemellologiae, 9, 387-406.

Gedda, L. (1961). Twins in history and science. Springfield, III.: Charles Thomas

Grebe, H. (1955). Sport bei Zwillingen. Acta Geneticae Medicae et Gemellologiae, 4, 275-295.

Guidetti, L., Baldari, C., Pittaluga, M., Parisi, P., \& Di Luigi, L. (1999). Lifestyle and anabolic/catabolic steroid-hormone balance in elderly males: A twin study. Proceedings of the 4th Annual Congress of the European College of Sport Science, Rome, 78, (Abstract).

Hamel, P., Simoneau, J. A., Lortie, G., Boulay, M. R., \& Bouchard, C. (1986). Heredity and muscle adaptation to endurance training. Medicine and Science in Sports and Exercise, 18, 690-96.

Klissouras, V. (1971). Heritability of adaptive variation. Journal of Applied Physiology, 31, 338-344.

Klissouras, V., Casini, B., Di Salvo, V., Faina, M., Marini, C., Pigozzi, F., et al. (2001). Genes and Olympic performance: A co-twin study. International Journal of Sports Medicine, 22, 250-255.

Kovar, R. (1975). Motor performance in twins. Acta Geneticae Medicae et Gemellologiae, 24, 174.

Kovar, R. (1981). Human variation in motor abilities and its genetic analysis. Prague: Charles University.

Lee, I-M., Paffenbarger, Jr. R. S., \& Hennekens, C. H. (1997). Physical activity, physical fitness and longevity. Aging in Clinical and Experimental Research, 9, 2-11.

Marisi, D. G. (1977). Genetic and extragenetic variance in motor performance. Acta Geneticae Medicae et Gemellologiae, 26, 197-204.

Monti, M., Barbieri, D., Capri, M., Salvioli, S., Drago, E., Maione, D., et al. (1999). Immunomodulatory effects of physical stress and training in the elderly. Proceedings of the 4 th Annual Congress of the European College of Sport Science, Rome, 104, (Abstract).

Parisi, P., Gatti, M., Prinzi, G., \& Caperna, G. (1983). Familial incidence of twinning. Nature, 304, 626-628.

Parisi, P., Casini, B., Pittaluga, M., Di Salvo, V., Pigozzi, F., Cilia, G., et al. (1996). Twin registers for sport science. Proceedings of the 1st Annual Congress of the European College of Sport Science, Nice, 538-539, (Abstract).

Parisi, P., Casini, B., Pittaluga, M., Prinzi, G., Di Salvo, V., Pigozzi, F., \& Klissouras, V. (1997). The Registry of Italian Twin Athletes (RITA): Establishment of a panel of twin swimmers. Proceedings of the 2nd Annual Congress of the European College of Sport Science, Copenhagen, 713-714, (Abstract).

Parisi, P., Pigozzi, F., \& Klissouras, V. (1998). Genetic limits of sport performance - A study on twin athletes. Report for ICSSPE and the IOC. Rome: ICSSPE \& IOC.

Parisi, P., Casini, B., Di Salvo, V., Pigozzi, F., Pittaluga, M., Prinzi, G., \& Klissouras, V. (2001). The Registry of Italian Twin Athletes (RITA). European Journal of Sport Science, 1(2), 1-12.

Persichini, C., Demarie, S., Capranica, L., Pittaluga, M., \& Parisi, P. (1999). Determinants of rhythmic ability: A pilot study on MZ and DZ elderly twins. Proceedings of the 4th Annual Congress of the European College of Sport Science, Rome, 478, (Abstract).

Pittaluga, M., Casini, B., \& Parisi, P. (1996). Physical activity, risk factors and aging: An epidemiological and clinical study on the elderly population. Proceedings of the 1st Annual Congress of the European College of Sport Science, Nice, 558-559, (Abstract).

Pittaluga, M., Casini, B., Prinzi, G., Urbinati, G., \& Parisi, P. (1999). The LISA project — Life style and aging in elderly twins. Proceedings of the 4th Annual Congress of the European College of Sport Science, Rome, 103, (Abstract).

Pittaluga, M., Casini, B., Prinzi, G., Urbinati, G., Taddei, F., \& Parisi, P. (2001 a). Heredity, lifestyle and personality in risk factors and aging: A study on twins. Journal of Sports Science, 19(8), 653-654.

Pittaluga, M., Argentin, G., Caporossi, D., Casini, B., Cicchetti, R., Tedeschi, (2001b). Cellular and molecular responses to aging in relation to physical activity: A study on elderly twins. Proceedings of the 6th Annual Congress of the European College of Sport Science, Cologne, 205, (Abstract).

Prud'Homme, D., Bouchard, C., Leblanc, C., Landry, F., $\&$ Fontaine, E. (1984). Sensitivity of maximal aerobic power to training is genotype dependent. Medicine and Sciences in Sports and Exercise, 16, 489-493.

Pulejo, C., Calcaterra, M. C., Cherubini, D., Pittaluga, M., \& Parisi, P. (1999). Assessment of balance performance in elder subjects: A twin study. Proceedings of the 4th Annual Congress of the European College of Sport Science, Rome, 482, (Abstract).

Saltin, B. (1969). Physiological effects of physical training. Medicine and Science in Sports and Exercise, 1, 50.

Sbriccoli, P., Rosponi, A., Felici, C., Palma, M., Pittaluga, M., Parisi, P., \& Figura, F. (1999). Neuromuscular fatigue in elderly: Influence of genetics factors. Proceedings of the 4th Annual Congress of the European College of Sport Sciences, Rome, 442, (Abstract).

Sklad, M. (1972). Similarity of movements in twins. Wychowanie Fizyezne i Sport, 16, 119-141.

Sklad, M. (1975). The genetic determination of the rate of learning of motor skills. Studies in Physiological Anthropology, 1, 3-19.

Vernole, P., Argentin, G., Caporossi, D., Tedeschi, B., Pittaluga, M., Parisi. (1999). Response to oxidative stress in lymphocytes of twins: Effects of aging, genetics, and physical activity. 
Proceedings of the 4th Annual Congress of the European College of Sport Science, Rome, 486, (Abstract).

Vernole, P., Argentin, G., Caporossi, D., Cicchetti, R., Parisi, P., Pittaluga, M., et al. (2002). Chromosome damage induced by bleomycin andlor aphydicolin in lymphocytes from monozygotic and dizygotic twins. Manuscript in preparation.
Weiss, V. (1979). Die Heritabilitäten sportlicher Test, berechnet aus den Leistungen zehnjähriger Zwillingspaare. Leistungssport, 9, 58-61.

World Health Organization. (1966). The use of twins in epidemiological studies: Report of the WHO meeting of investigators on methodology of twin studies. Acta Geneticae Medicae et Gemellologiae, 15, 111-128. 